\title{
Do patients matter? Contribution of patient and care provider characteristics to the adherence of general practitioners and midwives to the Dutch national guidelines on imminent miscarriage
}

\author{
Margot Fleuren, Madelaine van der Meulen, Dirk Wijkel
}

\begin{abstract}
Objective-To assess the relative contribution of patient and care provider characteristics to the adherence of general practitioners (GPs) and midwives to two specific recommendations in the Dutch national guidelines on imminent miscarriage. The study focused on performing physical examinations at the first contact and making a follow up appointment after 10 days because these are essential recommendations and there was much variation in adherence between different groups of providers.
\end{abstract}

Design-Prospective recording by GPs and midwives of care provided for patients with symptoms of imminent miscarriage. Setting-General practices and midwifery practices in the Netherlands.

Subjects-73 GPs and 38 midwives who agreed to adhere to the guidelines; 391 patients were recorded during a period of 12 months.

Main measures-Adherence to physical examinations and making a follow up appointment were measured as part of a larger prospective recording study on adherence to the guidelines on imminent miscarriage. Patient and care provider characteristics were obtained from case recordings and interviews, respectively. Multilevel analysis was performed to assess the contribution of several care provider and patient characteristics to adherence to two selected recommendations: the number of recommended physical examinations at the first contact and the number of days before a follow up appointment took place.

Results-In the multilevel model explaining variance in adherence to physical examinations, the care provider's acceptance of the recommendations was the most important factor. Severity of symptoms and referral to an obstetrician were significant factors at the patient level. In the model for follow up appointments the characteristics of the care provider were less important. Referral to an obstetrician and probability diagnosis were significant factors at the patient level.

Conclusions-The study showed that characteristics of both the patient and care provider contribute to the variability in adherence. Furthermore, the contribution of the characteristics differed per recommendation. It is therefore advised that the contribution of both patient and care provider characteristics per recommendation should be carefully examined. If implementation is to be successful, strategies should be developed to address these specific contributions. (Quality in Health Care 2000;9:106-110)

Keywords: guidelines; miscarriage; implementation

\section{Introduction}

One of the main problems in the implementation of guidelines is that care providers do not automatically adhere to them..$^{1-4}$ Grol uses a model consisting of four steps that are necessary in order to change routines and successfully implement guidelines ${ }^{56}$ : (1) care providers should be aware of the guidelines (orientation); (2) they should understand what the guidelines recommend and in which way their own routines differ from these recommendations (insight); (3) they should have a positive attitude towards the guidelines (acceptance); and (4) they should actually try to apply the guidelines in practice (implementation). This process does not seem to be of a linear nature. ${ }^{78}$ The way in which the guidelines are actually applied during the implementation phase might, for example, again lead to non-acceptance. Furthermore, several factors might either facilitate or hinder the implementation, such as the nature of the guidelines, the characteristics of the care provider, the characteristics of the patient, or the setting in which the guidelines are applied. ${ }^{2} 35$ 7-11

In 1989 the Dutch College of General Practitioners introduced national guidelines on imminent miscarriage for general practitioners (GPs). ${ }^{12}$ The guidelines are also applicable for midwives. A spontaneous miscarriage in the first 16 weeks of gestation occurs in approximately $10 \%$ of all pregnancies. ${ }^{13-14}$ Bleeding is usually the first sign of a miscarriage. In the Netherlands symptoms of imminent miscarriage are generally not considered to be an indication for referral to an obstetrician, so the care is mainly provided by independent midwives and GPs in primary health care.

The guidelines contain recommendations on history taking and diagnostic and therapeutic management (box 1). The fundamental assumption in the guidelines is that a miscarriage is a self-regulating process so, in cases where there are no complications, a "wait and see" policy is recommended, allowing events to take their normal course. To be able to detect com- 
plications, adherence to the recommendations on physical examination at the first appointment and a follow up appointment after 10 days for repeated physical examination is essential.

This paper presents a part of the results of a general evaluation of the guidelines on imminent miscarriage by GPs, midwives, obstetricians, and patients. In previous publications it has been shown that adherence to some essential recommendations - that is, performing physical examinations and making a follow up appointment after 10 days-was low. ${ }^{15}{ }^{16}$ Furthermore, there was also much variation in adherence between different groups of providers. The objective of this study is to determine which factors at provider level and which factors at patient level influence adherence to these recommendations. Knowledge of these factors can be of value to quality managers who wish to develop implementation strategies for the final step of the change model.

\section{Methods}

SUBJECTS AND PROCEDURE

In 1993 and 1994 two prospective registration studies were carried out in which 86 GPs and 56 midwives who agreed to adhere to the guidelines on imminent miscarriage recorded data from 407 patients with symptoms of imminent miscarriage. ${ }^{15} 16$ The GPs and mid-

\section{First appointment}

- GPs should ask questions on the history such as the duration and nature of blood loss or pain, having a temperature, or feeling ill.

- GPs should make a diagnosis themselves by carrying out the following examinations:

percussion and palpation of the abdomen;

speculum examination;

vaginal examination.

- In cases of uncomplicated imminent miscarriage GPs should "wait and see", which means:

explaining situation and, if possible, giving reassurance;

no ultrasound scan;

not referring the patient to an obstetrician.

- GPs should make a follow up appointment after 10 days. However, if the blood loss or pain increases, if the woman has a fever or is anxious, then she should contact the GP immediately.

Follow up appointment

- GPs should carry out the following examinations: percussion and palpation of the abdomen; speculum examination; vaginal examination.

- In cases of complete miscarriage or an intact pregnancy GPs should:

explain the situation;

not use ultrasound scan;

not refer to an obstetrician.

- In cases of incomplete miscarriage (that is, if the woman is still losing blood) GPs should: perform an ultrasound scan themselves (without referring to an obstetrician)

Care after miscarriage

- GPs should plan a counselling consultation after six weeks.

- GPs should only refer the patient to an obstetrician after three or more consecutive miscarriages to find out why she miscarried.

Box 1 Most important recommendations in the guidelines on imminent miscarriage. wives had previously received specific training, focusing on the first three steps of the change model (box 2). Over a 12 month period they recorded on a specially designed form every appointment made during surgery hours, every telephone call, and every visit that was made. At the end of the study all care providers were asked about a number of personal characteristics and whether or not they agreed with the recommendations (box 2).

\section{EXPLANATORY VARIABLES}

The characteristics of the care provider (age, sex, and acceptance of the recommendations of the guidelines) were obtained from the interviews. Acceptance of performing physical examinations was defined as the mean number of physical examinations with which the care provider agreed. The personal and medical characteristics of the patient (age, duration of pregnancy, duration of the complaints, severity of blood loss and pain, probability diagnosis, having an ultrasound scan, referral to an obstetrician) were obtained from the record form.

\section{Training}

All GPs and midwives received training by a registered $\mathrm{GP} /$ midwife and a researcher $(M F)$. The guidelines were sent to them beforehand and they were asked to indicate whether they accepted (yes/no) each recommendation as outlined in box 1 . Furthermore, they were asked to prepare two case histories and to discuss several cases from their own practice. During the training all recommendations were discussed. A great deal of time was spent on the customary management by the $\mathrm{GP} /$ midwife of imminent miscarriage and determining whether this was in accordance with the guidelines. Strategies for adherence were also discussed.

Analysis of adherence and acceptance Two researchers analysed adherence to the recommendations by means of a code list, developed by two researchers and two GPs on the basis of the guidelines. The two researchers independently coded the recommendations of 30 randomly chosen record forms to assess their reliability. A $\kappa$ coefficient of agreement of $\geqslant 0.76$ was obtained (Cohen's $\mathrm{K}$ adjusted for chance). At the end of the 12 month registration period all GPs and midwives were interviewed. Every patient seen by the GP/midwife was discussed in a structured telephone interview supported by copies of the record forms and the patient's charts. The GPs/midwives were asked to give their reasons for nonadherence. Furthermore, they were asked whether they agreed (yes/no) to each recommendation as outlined in box 1 .

Two researchers who conducted the interviews were given interview training beforehand by MF.

Box 2 Details on training and analysis of adherence and acceptance. 
DEPENDENT VARIABLES

Details on physical examinations (percussion and palpation, speculum examination and vaginal examination) and details on the follow up appointment were also obtained from the record form. Because percussion and palpation are highly related, they were considered as one single examination. As the guidelines recommend performing all "three" examinations, adherence to physical examinations was assessed on the basis of the number of physical examinations performed, ranging from 0 (none performed) to 3 (all three examinations performed).

The recommendation of a follow up appointment after 10 days was adapted for measurement purposes. Two GPs reached consensus and adherence was defined as a follow up appointment made within 7-14 days. Adherence to follow up appointment was therefore divided into three categories: $0=$ within one week; $1=$ within $1-2$ weeks; $2=$ after 2 weeks.

ANALYSIS OF DATA

Care providers who recorded no patients were excluded from the analyses. In group practices it is common for a patient to see different care providers. As the recommendations studied concerned the first contact, GPs and midwives who were not involved in this first contact were excluded. Furthermore, care providers and patients were excluded if data on important characteristics were missing. Differences between GPs and midwives were subjected to a $t$ test or a $\chi^{2}$ test.

As the characteristics of both the patient and care provider might influence adherence, a multilevel approach was taken. The most common approaches to analysing hierarchical data are either to perform an aggregate level analysis or an individual level analysis. ${ }^{17}$ The GP figures in table 2 can be used as an illustration. As these figures are presented at patient level, it can be seen, for instance, that $49 \%$ of all patients registered by GPs underwent percussion and palpation. This gives no indication of the percentage of GPs in the study who actually performed these examinations. In theory the percentage of GPs who adhere to the recommendation could be much lower if GPs with a large number of patients never perform these examinations. The multilevel approach has several advantages. Firstly, it takes advantage of the variance at both patient and care provider level. Secondly, it takes into account the fact that patients treated by a specific care provider tend to be more similarthat is, the dependency of residuals due to analysis at patient level is avoided. ${ }^{17}{ }^{18}$ Thirdly, it is possible to include care providers who only treat a small number of patients. ${ }^{19}$

Multilevel analysis is a sophisticated statistical method with which all the observed variation, at both patient and provider level, can be applied in the research. ${ }^{20}{ }^{21}$ Finding an appropriate explanatory model for the observed reality is an interesting process, but goes beyond the scope of this paper. Only the best fitting models are therefore presented. These demonstrate the effects of explanatory variables at both levels.
Included in the procedures to find the best fit is residual analysis of the dependent variables. It might not be valid to assume that each care provider responds in the same way to the patient and contact characteristics. By allowing in the model a different handling of some of these characteristics by the care provider, it is possible to investigate the variations between care providers. This analysis was performed for all the explanatory variables.

\section{Results}

PERSONAL, MEDICAL AND CONTACT CHARACTERISTICS

Of the 86 GPs, 11 were excluded because they had recorded no patients and another two were excluded because of missing data on important variables. Of the 56 midwives, 15 were excluded because they had recorded no patients or had not been involved in the first contact, and another three were excluded because of missing data on important variables. The remaining 73 GPs recorded 241 patients (mean 3.3 per GP) and the 38 midwives recorded 150 patients (mean 3.9). The breakdown in terms of age, sex, and membership of a professional organisation showed that the respondents were representative of the national population of GPs and midwives.

The midwives differed from the GPs with regard to their mean age (36 and 44 years, respectively; $\mathrm{p}<0.01, t$ test). Furthermore, all the midwives were female whereas only $22 \%$ of the GPs were women $\left(\mathrm{p}<0.01, \chi^{2}\right.$ test). There was no difference with regard to acceptance of the recommendations on physical examinations and a follow up appointment. Of the GPs, $51 \%$ agreed with the follow up appointment and the mean number of physical examinations agreed with was 2.0 . Of the midwives, $34 \%$ agreed with the follow up appointment and the mean number of physical examinations agreed with was 1.7. The patients seen by the GPs and midwives differed with regard to the duration of their pregnancy and complaints, the type of complaints, and their probability diagnosis. Furthermore, they also differed with regard to the diagnostics applied (table 1). The level of adherence to the most important recommendations is shown in table 2 and clearly illustrates the differences between GPs and midwives, particularly with regard to the performance of a speculum examination and the follow up appointment within 7-14 days. This raises the question of whether these differences should be attributed to differences between care providers or differences in the patient populations, or both.

FACTORS DETERMINING ADHERENCE TO PHYSICAL EXAMINATIONS

The results of multilevel analysis of physical examinations in which the variation at the patient level and at the care provider level are studied simultaneously are presented in table 3. The variance is explained separately for patients and care providers. The probability diagnosis groups are excluded because they are not "explanatory" for the first contact. "Duration of pregnancy" and "duration of com- 
Table 1 Differences in personal, medical, and contact characteristics between patients of GPs $(n=241)$ and patients of midwives $(n=150)$

\begin{tabular}{|c|c|c|}
\hline Patient characteristics & $G P s$ & Midwives \\
\hline \multicolumn{3}{|l|}{ Personal characteristics } \\
\hline Mean age (years) & 29.6 & 29.4 \\
\hline \multicolumn{3}{|l|}{ Medical characteristics } \\
\hline Mean duration of pregnancy (weeks) & 8.6 & $10.4^{\star}$ \\
\hline Mean duration of complaints (hours) & 44.7 & $32.0^{\star \star}$ \\
\hline \multicolumn{3}{|l|}{ Blood loss $†$} \\
\hline No blood loss (\%) & 4 & $9 \star \star \star$ \\
\hline$\leqslant$ own menses $(\%)$ & 77 & 70 \\
\hline$>$ own menses $(\%)$ & 19 & 21 \\
\hline Pain (\%) & 45 & 41 \\
\hline \multicolumn{3}{|l|}{ Probability diagnosis $\ddagger$} \\
\hline Imminent miscarriage (\%) & 78 & 83 \\
\hline Complete miscarriage (\%) & 10 & 9 \\
\hline Incomplete miscarriage (\%) & 6 & $13^{\star \star}$ \\
\hline Intact pregnancy $(\%)$ & 15 & 20 \\
\hline Portio erosion (\%) & 2 & $13^{\star}$ \\
\hline Ectopic pregnancy, molar pregnancy, premalignant disease (\%) & 2 & 1 \\
\hline \multicolumn{3}{|l|}{ Contact characteristics } \\
\hline Having had an ultrasound scan (\%) & 9 & $32^{\star}$ \\
\hline Having been referred to obstetrician (\%) & 9 & 11 \\
\hline Mean no. of physical examinations & 1.82 & $1.2^{\star}$ \\
\hline Follow up appointment (weeks) & 0.98 & $0.74^{\star}$ \\
\hline
\end{tabular}

${ }^{{ }_{\mathrm{p}}}<0.01,{ }^{\star \star} \mathrm{p}<0.05$ significant difference between patients of GPs and midwives ( $t$ test or $\chi^{2}$ test). †The guidelines advise relating the amount of blood loss to the patient's normal menses: $\leqslant$ own menses or $>$ own menses.

$\ddagger$ More than one probability diagnosis possible.

plaints" (the longer the pregnancy or the complaints, the more physical examinations performed), "no blood loss", and "referral to an obstetrician" (both implying fewer physical examinations) are significant predictors for the number of physical examinations performed. Acceptance of performing physical examinations by the care provider appears to be a strong predictor for the number of physical examinations actually performed. The explained variance in the model is $9 \%$ at the patient level and 53\% at the care provider level, and the distribution of residuals at both levels is approximately normal.

FACTORS DETERMINING ADHERENCE TO FOLLOW UP APPOINTMENT

The best fitting model for the follow up appointment is presented in table 4. The patient characteristics "duration of pregnancy" (the longer the pregnancy, the sooner the appointment) and "referral to obstetrician" (with a referral the appointment is made later) are significant predictors of making a follow up appointment. Furthermore, women with the probability diagnosis of "portio erosion" or "intact pregnancy" had a later follow up appointment. The model shows no significant care provider predictors. After careful analysis, the variable "having an ultrasound scan" was added to the model so that different handling by the care provider was allowed. The ex-

Table 2 Percentage of patients for whom GPs and midwives adhered to the most important recommendations for the first contact (per care provider)

\begin{tabular}{lll}
\hline Recommendation & $\begin{array}{l}\text { Patients of } \\
\text { GPs }(n=241)\end{array}$ & $\begin{array}{l}\text { Patients of midwives } \\
(n=150)\end{array}$ \\
\hline Percussion and palpation & 49 & $59^{\star}$ \\
Speculum examination & 68 & $17^{\star \star}$ \\
Vaginal examination & 65 & $45^{\star}$ \\
Follow up within 7-14 days & 61 & $33^{\star \star \star}$ \\
Ultrasound scan & 93 & $70^{\star \star}$ \\
Referral to obstetrician & 93 & 91
\end{tabular}

${ }^{\star} \mathrm{p}<0.01,{ }^{\star \star} \mathrm{p}<0.001,{ }^{\star \star \star} \mathrm{p}<0.05$ significant difference between GPs and midwives ( $t$ test).
Table 3 Final multilevel regression model of physical examinations ${ }^{*}$, parameter estimates and $t$ ratiost

\begin{tabular}{ll}
\hline & $\begin{array}{l}\text { Final model, } \\
\text { parameter }(\text { t ratio) }\end{array}$ \\
\hline Patient variables & \\
Age & $-0.016(-1.48)$ \\
Duration of pregnancy & $\mathbf{0 . 0 4 3}(2.07)$ \\
Duration of complaints & $\mathbf{0 . 0 0 2}(2.26)$ \\
No blood loss & $\mathbf{- 0 . 5 6 1}(-2.69)$ \\
Much blood loss & $0.107(0.82)$ \\
Pain & $0.198(1.90)$ \\
Ultrasound scan & $-0.035(-0.24)$ \\
Referral to obstetrician & $-\mathbf{0 . 3 5 0}(-2.03)$ \\
Care provider variables & \\
Age & $-0.012(-1.22)$ \\
Sex (female) & $0.268(1.11)$ \\
Midwife & $-0.296(-1.22)$ \\
Acceptance & $\mathbf{0 . 3 8 1}(5.33)$ \\
Explained variance (patients) & $9 \%$ \\
Explained variance (care providers) & $53 \%$ \\
\hline
\end{tabular}

* Terms are defined as in table 1 and in the Results section. IIf the $t$ ratio exceeds \pm 1.96 , the estimate is considered to be significantly different from zero at the 0.05 level.

Table 4 Final multilevel regression model of follow up appointment ${ }^{*}$, parameter estimates and t ratiost

\begin{tabular}{ll}
\hline & $\begin{array}{l}\text { Final model, } \\
\text { parameter }(\text { t ratio) }\end{array}$ \\
\hline Patient variables & \\
Age & $-0.001(-0.08)$ \\
Duration of pregnancy & $-\mathbf{0 . 0 3 0}(-2.04)$ \\
Duration of complaints & $0.001(1.95)$ \\
No blood loss & $0.263(1.77)$ \\
Much blood loss & $0.011(0.11)$ \\
Pain & $-0.069(-0.96)$ \\
Ultrasound scan & $-0.153(-1.18)$ \\
Referral to obstetrician & $\mathbf{0 . 7 0 3}(5.70)$ \\
Probability diagnosis groups & \\
$\quad$ Complete miscarriage & $0.169(1.40)$ \\
$\quad$ Incomplete miscarriage & $0.120(0.91)$ \\
$\quad$ Intact pregnancy & $\mathbf{0 . 2 1 4}(2.26)$ \\
$\quad$ Portio erosion & $\mathbf{0 . 4 6 8}(3.23)$ \\
Ectopic, molar, premalignant & $0.434(1.35)$ \\
Care provider variables & \\
Age & $0.004(0.67)$ \\
Sex (female) & $0.076(0.54)$ \\
Midwife & $-0.196(-1.29)$ \\
Acceptance & $0.094(1.10)$ \\
Explained variance (patients) & $23 \%$ \\
Explained variance (care providers) & $25 \%$ \\
\hline
\end{tabular}

* Terms are defined as in table 1 and in the Results section. tIf the $t$ ratio exceeds \pm 1.96 , the estimate is considered to be significantly different from zero at the 0.05 level.

plained variance in this model is $23 \%$ at the patient level and $25 \%$ at the care provider level, and residual analysis shows a near normal distribution at both levels.

\section{Discussion}

Multilevel analysis of the adherence to recommendations on performing physical examinations reveals that specific (medical) patient characteristics play a significant but minor role in the decisions made by GPs and midwives. Of course, only a guess can be made as to what really triggered the performance of physical examinations, but there are indications that the perception of minor severity-for instance, if there is no blood loss-might be a plausible explanation. ${ }^{15}{ }^{16}$ On the other hand, a longer duration of the pregnancy or the complaints might arouse increased vigilance. It seems logical not to perform a physical examination if a patient is referred to an obstetrician who will perform the necessary examinations as a matter of course. Although non-acceptance of the guidelines on imminent miscarriage was a reason for exclusion from the study, consider- 
able scepticism was found among care providers with regard to the validity of physical examinations, particularly at an early stage of pregnancy. ${ }^{15} 16$

As stated earlier, the process of implementing guidelines does not seem to be of a linear nature. In trying to put the guidelines into practice (implementation) a care provider might, on second thoughts, not agree with them (non-acceptance). This non-acceptance contributed strongly to the predictive power of the explanatory model for physical examination in which $53 \%$ of this variance is explained by characteristics of the care provider, particularly the care provider's acceptance of the physical examinations. The explained variance at the patient level is only $9 \%$.

In the model for "making a follow up appointment" referral to an obstetrician is again of importance. If a patient is referred, the follow up appointment is postponed. The same applies to patients with the probability diagnosis of "intact pregnancy" or "portio erosion". It seems that, for these conditions, care providers are reluctant to make a short term appointment. A longer duration of pregnancy might again arouse vigilance and lead to a short term appointment. The significant improvement in explanatory power after the inclusion of "having an ultrasound scan" implies that the variation is independent of both the patient and care provider, implying that care providers do not all respond to their patients in the same way. This means that some care providers may, for example, perform a routine ultrasound scan and also make a follow up appointment for their patients whereas, for similar patients, other care providers would perform a routine ultrasound scan but would not make a follow up appointment. After the inclusion of the "having an ultrasound scan" factor the explained variance at both patient and care provider level is almost equal at $23 \%$ and $25 \%$, respectively.

The multilevel approach proves to be a powerful tool in analysing complex matters such as the factors that influence the performance of care providers. The results of this study show that characteristics of both the patient and care provider explain the variation in adherence. Furthermore, they show that different characteristics play a part in each recommendation. This information could be beneficial in updating the guidelines, on the one hand, and in developing special training programmes on implementation, on the other. Although certain main categories of facilitating or impeding factors can be distinguished in general in implementing guidelines, it is thought that most factors are related to specific settings or specific recommendations. The findings of this study confirm the supposition that both patient and care provider characteristics influence adherence. Furthermore, the results show that the contribution of patient and care provider characteristics may differ per recommendation with more influence by the care provider on the physical examinations and equal influence by care providers and patients on the follow up appointment. The answer to the question: "Do patients matter?" must therefore be affirmative and it is advised that the contribution of characteristics of both the patient and the care provider to each recommendation should be carefully examined. If implementation is to be successful, strategies should be developed to address these specific contributions.

As shown in table 2, adherence to the recommendations on physical examinations and a follow up appointment was low. The results show that $53 \%$ of the variance in adherence to the recommendations on physical examinations could be explained by acceptance of these recommendations by the care providers. It is therefore suggested that the Dutch College of General Practitioners should critically review these recommendations because it has been found that they are not generally accepted. Furthermore, it is suggested that, in special training programmes on the implementation of the guidelines, attention should be paid to the influence of (medical) patient characteristics on non-adherence to both the performance of physical examinations and the making of a follow up appointment.

1 Grol R. Development of guidelines for general practice care. Br F Gen Pract 1993;43:146-51.

2 Lomas J. Teaching old (and not so old) docs new tricks: effective ways to implement research findings. In: Dunn EV, Norton PG, Stewart M, et al, eds. Disseminating research/changing practice. London: Sage, 1994: 1-18.

3 Grimshaw J, Freemantle N, Wallace S, et al. Developing and implementing clinical practice guidelines. Quality in Health Care 1995;4:55-64.

4 Forrest D, Hoskins A, Hussey R. Clinical guidelines and Forrest D, Hoskins A, Hussey R. Clinical guidelines
their implementation. Postgrad Med f 1996;72:19-22.

5 Grol R. Implementing guidelines in general practice care. Quality in Health Care 1992;1:184-91.

6 Grol RTPM, Van Everdingen JJE, Casparie AF. Invoering van richtlijnen en veranderingen. (The implementation of guidelines and change). Utrecht: De Tijdstroom, 1994.

7 Fleuren M. Managing (imminent) miscarriage in primary health care. An evaluation of the (imminent) miscarriage guideline of the Dutch College of General Practitioners by general practitioners, midwives, obstetricians and patients. Thesis. Amsterdam: Vrije Universiteit, 1997.

8 Pathman DE, Kallich JD, Kahan JP. Dissemination of effectiveness and outcomes research. Health Policy 1995;34:

9 Conroy M, Shannon W. Clinical guidelines: their implementation in general practice. Br F Gen Pract 1995;45:371-5.

10 Woolf SH. Practice guidelines: what the family physician should know. Am Family Physician 1995;51:1455-63

11 Kanouse DE, Kallich JD, Kahan JP. Dissemination of effectiveness and outcomes research. Health Policy 1995;34: 167-92.

12 Flikweert S, Ligtenberg WJJ, Sips AJBI. Standaard (dreigende) miskraam. (Guidelines on (threatened) miscarriage). Huisarts en Wetenschap 1989;32:138-43.

13 Miller JF, Williamson E, Glue J, et al. Fetal loss after implantation. A prospective study. Lancet 1980;ii:554-6.

14 Wilcox AJ, Weinberg CR, O'Connor JF, et al. Incidence of early loss of pregnancy. N Engl f Med 1988;319:189-94.

15 Fleuren M, Grol R, De Haan M, et al. Adherence by midwives to the Dutch national guidelines on threatened miscarriage: a prospective study. Quality in Health Care 1997;6:69-74.

16 Fleuren M, Wijkel D, De Haan M, et al. Feasibility of guidelines for the management of threatened miscarriage in general practice/family medicine. Eur F Gen Pract 1998;4:11-7.

17 Rice N, Leyland A. Multilevel models: applications to health data. $\mathcal{F}$ Health Serv Res Policy 1996;1:154-64.

18 Duncan G, Jones K, Moon G. Health-related behaviour in context: a multilevel modelling approach. Soc Sci Med 1996;42:817-30.

19 Hox J J. Applied multilevel analysis. Amsterdam: TT Publikaties, 1995.

20 Woodhouse G. A guide to multilevel analysis for new users. London: Institute of Education, University of London, 1995.

21 Bryk AS, Raudenbush SW. Hierarchical linear models: applications and data analysis methods. Newbury Park: Sage, 1993. 